\section{Finland invites you: to this issue of BJSM and to Helsinki on 8-9 June 2018}

\author{
Peter Halén, ${ }^{1}$ Karim M Khan ${ }^{2}$
}

Welcome to this issue of the British Journal of Sports Medicine (BJSM) guest edited by the Finnish Sports Physiotherapy Association. Our 2018 sports PT conference will focus on the shoulder but this issue contains much more than that. Let's start at home (for us).

\section{THIS ISSUE}

We are proud of our elite athletes and it looks like their combination of genetics and environment leads to longer life but beware of the risk of knee arthritis following knee injuries (see page 89). Do elite athletes return to play at a greater rate than journeymen and journeywomen? The PhD research of Courtney Chun Han Lai (see page 128) seems to say yes! Keep $83 \%$ in mind as compared with the $55 \%$ that is often quoted from one of BJSM's most downloaded and most cited papers of $2015 .{ }^{1}$ Still on the lower limb, check out the surprising result of video analysis of ankle sprains (see page 74) in the sport designed for ankle sprain research - indoor volleyball. Improved technology/ methods-new light on an old problem. Can there be an issue of BJSM without adding to the hamstring debate? The prolific Dutch/Qatar hamstring authors provide data (see page 83 ) to suggest that in the presence of good clinical assessment, MRI is not necessarily needed in the suspected intramuscular hamstring tendon tear. That condition is generating a lot of debate. $^{2-4}$

\section{SHOULDER PEARLS}

Shoulder aficionados have enjoyed terrific recent papers in BJSM (see volume 51, issue 24). We have more for you here and at our Annual Conference in Helsinki in June. Scapular dyskinesis is a hot topic. Does it exist? How does one assess it? Is it a cause of shoulder pain or merely a by-product?

\footnotetext{
${ }^{1}$ The Finnish Sports Physiotherapist Association (FSPA), Helsinki, Finland

${ }^{2}$ Department of Family Practice, The University of British Columbia, British Columbia, Canada
}

Correspondence to PT Peter Halén, The Finnish Sports Physiotherapist Association, Helsinki, Finland; peter.halen@suft.fi

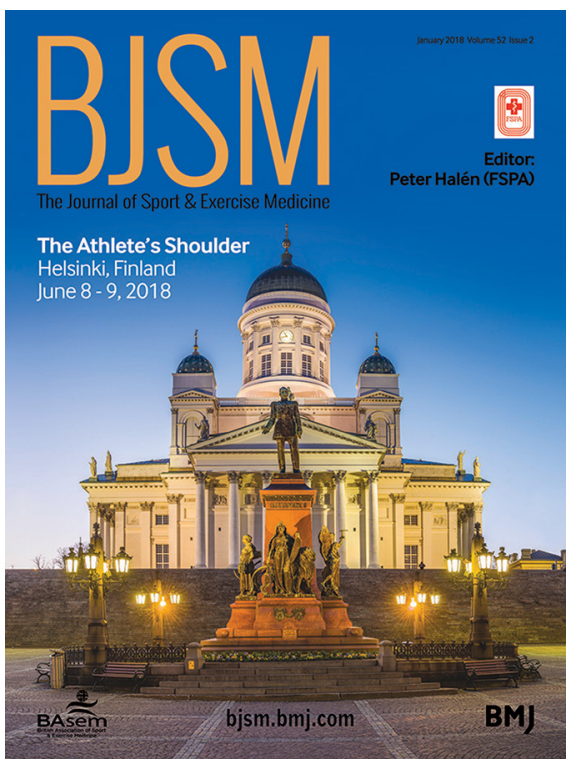

The systematic review provides the data (see page 102), for which Drs Chris Littlewood and Ann Cools provide context (see page 72). There's also a review suggesting that 3-4 weeks postoperatively is the best time to mobilise shoulders after rotator cuff repair (see page 111). What's your take? You can comment on BJSM's Google+page, or via Twitter, Facebook or the Blog. You can even make a video and post it. So many choices! Speaking of YouTube-don't forget that BJSM provides a full suite of physical examination videos (including of the shoulder) here: http://ow.ly/rLgo30gSVoX. They have been viewed $>6.5$ million times! And here's a teaser for the Annual Conference in Helsinki in June: http://fspa-congress. com/.

\section{HELSINKI: WHERE THE SHOULDER EXPERTS ARE MEETING IN 2018 - YOU CAN JOIN!}

Here's the scoop about Helsinki.

Our English language international from the trusted President of the World Confederation of Physical Therapy, Dr Emma Stokes, in 2017 and our programme sports physio conference got rave reviews for 2018 is even deeper in talent. Phil Glasgow, Jeremy Lewis, Saara Ketola are global leaders in sport PT. Jeremy Lewis is running a pre-conference workshop on June 6 and 7. Numbers are limited for that one. Here's a link: https://www.londonshoulderclinic.com/.

Enjoy this issue of BJSM and congratulations to the authors. The Editor in Chief tells me that fewer than $10 \%$ of submissions make it to these pages. Our Finnish Association of Sport Physiotherapy is going from strength to strength (in membership numbers, educational events) and we appreciate being among the 25 BJSM member societies. If you are a Finnish Sports PT and not a member of our Association please consider joining. You get great educational benefits, full access to all of BJSM and we are stronger together when we advocate for our profession. I look forward to reuniting with the large Finnish Sport Physiotherapy community in June alongside many international guests. "Terveisin" (Best wishes!)

\section{Competing interests None declared.}

Provenance and peer review Commissioned; internally peer reviewed.

(C) Article author(s) (or their employer(s) unless otherwise stated in the text of the article) 2018. All rights reserved. No commercial use is permitted unless otherwise expressly granted.

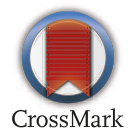

To cite Halén $\mathrm{P}$, Khan KM. Br J Sports Med 2018;52:71

Br J Sports Med 2018;52:71.

doi:10.1136/bjsports-2017-098883

\section{REFERENCES}

1 Ardern CL, Taylor NF, Feller JA, et al. Fifty-five per cent return to competitive sport following anterior cruciate ligament reconstruction surgery: an updated systematic review and meta-analysis including aspects of physical functioning and contextual factors. Br J Sports Med 2014;48:1543-52.

2 Brukner P, Connell D. 'Serious thigh muscle strains': beware the intramuscular tendon which plays an important role in difficult hamstring and quadriceps muscle strains. Br J Sports Med 2016;50:205-8

3 van Dyk N, Bahr R, Burnett AF, et al. A comprehensive strength testing protocol offers no clinical value in predicting risk of hamstring injury: a prospective cohort study of 413 professional football players. Br J Sports Med 2017;51:1695-702.

4 Wangensteen A, Bahr R, Van Linschoten R, et al. MR appearance does not change in the first 7 days after acute hamstring injury-a prospective study. Br J Sports Med 2017;51:1087-92. 